\title{
Enhanced Responses of Spinothalamic Tract Neurons to Excitatory Amino Acids Accompany Capsaicin-induced Sensitization in the Monkey
}

\author{
P. M. Dougherty and W. D. Willis \\ Department of Anatomy and Neurosciences, Marine Biomedical Institute, University of Texas Medical Branch, \\ Galveston, Texas $77550-2772$
}

\begin{abstract}
Sensitization of the responses of dorsal horn neurons to mechanical stimulation may play a role in the generation of hyperalgesia. Intradermal injection of capsaicin (CAP) provides a model of experimental hyperalgesia that possesses a component of allodynia. This hyperalgesia is produced by chemical stimulation of C-fibers, leading to sensitization of dorsal horn neurons, including spinothalamic tract (STT) cells. The changes in the physiological responses of STT neurons following intradermal CAP in monkeys parallel the acute pain and hyperalgesia produced by intradermal CAP in humans. The present study addresses the role that excitatory amino acids (EAAs) may play in the sensitization of STT neurons by intradermal CAP. Our results show that the background discharge rate and the responses of STT cells to mechanical stimulation increase following intradermal CAP. In addition, the responses of the sensitized cells to one or more iontophoretically released EAA agonists, including NMDA, glutamate, aspartate, kainate, DL- $\alpha$-amino-3-hydroxy-5-methylisoxazoleproprionic acid, and/or quisqualate, increase following intradermal CAP. It is proposed that an increase in the responses of STT neurons to EAAs contributes to the hyperalgesia produced by this noxious chemical stimulus.
\end{abstract}

Tissue damage, as well as injury to peripheral nerves or interruption of the spinothalamocortical pathway, can result in spontaneous pain and also in hyperalgesia and often allodynia (Lewis, 1942; Hardy et al., 1952; Boivie et al., 1989). Hyperalgesia is a condition in which there is an increase in the pain produced by a stimulus that is normally painful, and allodynia is pain produced by a stimulus that is not normally painful (Mersky, 1986). Hyperalgesia due to tissue damage is further subdivided into primary hyperalgesia, which occurs at the site of injury, and secondary hyperalgesia, which occurs in the surrounding undamaged tissue (Hardy et al., 1952).

An increase in the excitability of nociceptive spinal neurons, including sensory projection neurons of the dorsal horn, has been demonstrated in several experimental models of hyperalgesia (Kenshalo et al., 1979, 1982; Woolf, 1983; Ferrington

\footnotetext{
Received July 30, 1991; revised Oct. 17, 1991; accepted Oct. 18, 1991.

We thank Kelli Gondesen for technical assistance and Griselda Gonzales for assistance with the illustrations. This effort was supported by NIH Grants NS09743 and NS1 1255, National Service Award NS08860, and an unrestricted grant from the Bristol-Myers Squibb Company.

Correspondence should be addressed to W. D. Willis, Jr., M.D., Ph.D., Department of Anatomy and Neurosciences, Marine Biomedical Institute, University of Texas Medical Branch, 200 University Boulevard, Galveston, TX 77550-2772. Copyright (C) 1992 Society for Neuroscience $0270-6474 / 92 / 120883-12 \$ 05.00 / 0$
}

et al., 1987; Schaible et al., 1987; Schouenborg and Dickenson, 1988; Woolf and Thompson, 1991; Dougherty et al., in press). One such model is that produced by intradermal injections of capsaicin (CAP) (Simone et al., 1987, 1989, 1991). The responses of spinothalamic tract (STT) neurons increase to noxious heat at the injection site and to mechanical stimulation in the area surrounding the injection site (Simone et al., 1991). Moreover, the magnitude and duration of the responses of STT neurons to these stimuli parallel the reports from humans of the spontaneous pain and increased sensitivity to stimulation of the skin produced by intradermal CAP (LaMotte et al., 1991). The changes in responsiveness to stimulation at the injection site provide a model of primary hyperalgesia, and those to stimulation in the surrounding area, a model of secondary hyperalgesia (cf. Lewis, 1942; Hardy et al., 1952).

CAP induces its physiological effects through an action on a subset of C-polymodal nociceptors as well as a novel set of chemosensitive C-fibers (Porszasz and Jansco, 1959; Handwerker et al., 1984; Lynn and Shakhanbeh, 1988; Baumann et al., 1991; cf. Handwerker et al., 1991). Stimulation of these fibers would be expected to cause the release of transmitters found in unmyelinated fibers, including substance $P(S P)$, calcitonin generelated peptide (CGRP), and excitatory amino acids (EAAs), into the dorsal horn of the spinal cord (Hokfelt et al., 1975; McNeill et al., 1989; Westlund et al., 1989, 1990b). Release of SP (Olgart et al., 1977; Gamse et al., 1979, 1981) and EAAs (Liu et al., 1990) following CAP administration has been demonstrated. Since these substances are found in synaptic contacts upon STT neurons, a direct action upon this dorsal horn neuron subtype would be expected (Carlton et al., 1985, 1990; Westlund et al., 1990a), as well as indirect actions through interneuronal pathways. We have recently shown that combined iontophoretic release of an EAA, NMDA, and SP in the vicinity of STT neurons causes a long-lasting increase of the responses of the STT neurons to later applications of the same EAA (Dougherty and Willis, 1991). This increase in EAA response is accompanied by an increase in the responses of the neurons to mechanical stimulation of their receptive fields. A similar increase of STT responses to EAAs is observed following the induction of mechanical hyperalgesia in a model of acute experimental arthritis (Dougherty et al., in press). This raises the question of the possible role that such a potentiation of EAA responses by CAP may play in the hyperalgesia produced by intradermal injection of this substance. To test this possibility, we have examined the responses of STT neurons to iontophoretically applied EAAs before and then following the sensitization of STT cells produced by intradermal CAP in monkeys. 
A preliminary report of some of these findings has been made (Willis and Dougherty, 1991).

\section{Materials and Methods}

Animal preparation. A total of 16 young adult monkeys (Macaca fascicularis) weighing $2.1-3.0 \mathrm{~kg}$ were initially anesthetized by ketamine $(10.0 \mathrm{mg} / \mathrm{kg}$, i.m.) for transportation to the laboratory. Anesthesia was reestablished with a gaseous mixture of halothane, nitrous oxide, and oxygen followed by intravenous $\alpha$-chloralose $(60.0 \mathrm{mg} / \mathrm{kg})$. Anesthesia was then maintained by intravenous infusion of pentobarbital $(5.0 \mathrm{mg} /$ $\mathrm{kg} / \mathrm{hr}$ ). The level of anesthesia was monitored frequently by examination of pupillary size and reflexes and stability of expired $\mathrm{CO}_{2}$ and heart rate. The monkeys were paralyzed with gallamine triethiodide $(20.0 \mathrm{mg} / \mathrm{hr})$ and ventilated artificially. End-tidal $\mathrm{CO}_{2}$ was maintained between $3.5 \%$ and $4.5 \%$, and rectal temperature was kept between $37^{\circ} \mathrm{C}$ and $38^{\circ} \mathrm{C}$ by a servo-controlled heating blanket. All procedures were reviewed by the local animal care committee and were consistent with the guidelines accepted by the International Association for the Study of Pain and the NIH guide for the care and use of laboratory animals.

$A$ laminectomy exposed the lumbar enlargement, and the spinal cord was covered by a pool of warmed mineral oil. A partial craniotomy allowed placement of a stainless steel monopolar electrode in the ventral posterior lateral nucleus of the right thalamus (VPL; A $8.0 \mathrm{~mm}, \mathbf{L} 8.0$ $\mathrm{mm}, \mathrm{H} 16.0-18.0 \mathrm{~mm}$ ); the location was verified by recording responses evoked by electrical stimulation of the left dorsal funiculus and by mechanical stimulation of the left distal hindlimb.

Experimental protocol. A seven barrel micropipette was used to apply drugs by microiontophoresis and to record single-unit discharges in the spinal cord (Willcockson et al., 1984a,b; Dougherty and Willis, 1991; Dougherty et al., in press). Extracellular activity was monitored through the center barrel, which contained a low-impedance (2-3 M $\Omega$ ) carbon filament electrode, and drugs were delivered from the surrounding outer barrels. Unit activity was monitored on storage and digital oscilloscopes and simultaneously fed to a window discriminator interfaced with a computer for data storage and later analysis. Individual spike configuration and size were continuously monitored on a digital oscilloscope to confirm that the same cell was registered by the window discriminator throughout the experiment. This was found useful to ensure that orientation of the recording electrode to the target cell was maintained and to exclude the discharges of neighboring cells. The storage oscilloscope was used to monitor overall activity of the neurons. STT neurons were isolated using antidromic search stimuli $(0.75 \mathrm{~mA}, 200 \mu \mathrm{sec}$, at $0.3 \mathrm{~Hz})$ passed through the VPL electrode. The antidromic spikes occurred at fixed latency, showed collision with orthodromic spikes at appropriate intervals, and followed high-frequency $(333-500 \mathrm{~Hz})$ stimulus trains.

The experiment on each cell began with the determination of control mechanically and chemically evoked activity. Receptive fields were mapped with innocuous and noxious mechanical stimuli using a camel hair brush, finger taps, and brief applications of arterial clips to the skin. Five test points were then chosen and marked with permanent ink for delivery of a series of three graded intensities of mechanical stimuli. The five test points spanned the receptive field when the field was large, but sometimes extended outside a medium-sized or small receptive field. The mechanical stimuli included brushing the skin with a camel hair brush in a stereotyped manner (BRUSH) and then sustained applications of two different-sized arterial clips to a fold of skin. The large clip (PRESS) produces a force of $144 \mathrm{gm} / \mathrm{mm}^{2}$ and induces a sense of firm pressure near threshold for pain when placed on human skin. The second clip (PINCH) has a force of $583 \mathrm{gm} / \mathrm{mm}^{2}$ and is distinctly painful. Prior to application of the mechanical stimuli, 2 min of background activity was recorded. The stimulus series began with an additional recording of 10 sec of background activity, and then the BRUSH stimulus was applied to test point 1 for $10 \mathrm{sec}$; after a $10 \mathrm{sec}$ pause, the stimulus was applied to test point 2 for $10 \mathrm{sec}$. This sequence was followed until the stimulus had been applied to all five test sites. After the BRUSH stimuli had been delivered, the entire sequence was repeated twice more, first with the PRESS and then with the PINCH stimulus. Care was taken to ensure that the BRUSH responses on each occasion were maximal and that the PRESS and PINCH stimuli were applied to the same marked location and the responses obtained while allowing the clips to hang freely from the skin. Only a single series of mechanical stimuli was generally applied before injection of CAP; however, control experiments showed that repeated application of these nondamaging stimuli elicited consistent responses (Dougherty et al., in press). One or more series of mechanical stimuli were applied after CAP, depending on whether or not the responses were to be followed to recovery. Although the responses were not obtained by "blinded" investigators, they were obtained over prolonged periods from multiple locations and without observation of the oscilloscopes or the computerized record; hence, the investigators were "operationally blinded." Responses to mechanical stimuli were later used to categorize the cells as wide dynamic range (WDR) or high threshold (HT), depending on which stimulus or combination of stimuli activated the cells best. WDR cells responded to all three mechanical stimuli, whereas HT cells responded weakly to BRUSH ( $10 \%$ or less of the maximal response) or not at all.

The substances used in the microiontophoresis experiments included $N$-methyl-D-aspartic acid (NMDA; $0.05 \mathrm{M}, \mathrm{pH} 8.0$ ), L-glutamic acid (GLUT; $0.1 \mathrm{M}, \mathrm{pH} 8.0$ ), L-aspartic acid (ASP; $0.1 \mathrm{M}, \mathrm{pH} \mathrm{8.0),} \mathrm{DL-} \alpha-$ amino-3-hydroxy-5-methyl-isoxazoleproprionic acid (AMPA; $0.025 \mathrm{M}$, $\mathrm{pH}$ 8.0), L-kainic acid (KAIN; $0.1 \mathrm{~m}, \mathrm{pH} 8.0$ ), and quisqualic acid (QUIS; $0.05 \mathrm{M}, \mathrm{pH} 8.0$ ). These substances were obtained from Sigma Chemical Corporation or Research Biochemicals Incorporated. In all experiments, one barrel was filled with $2 \mathrm{M} \mathrm{NaCl}(\mathrm{pH} \mathrm{8.0)}$ for current balance. Retaining currents sufficient to prevent drug leakage (usually 3-8 nA) were used between drug applications. Net current at the electrode tip was continuously monitored and neutralized with the aid of a Medical Systems iontophoresis pump (model $\mathrm{BH}-2$ ).

EAAs were applied by five 10 -sec-long current pulses (or in some cases $5 \mathrm{sec}$ pulses) that were incremented in steps of either 5 or $10 \mathrm{nA}$. Additional drug applications were made after allowing the cell to resume its baseline discharge rate over 3-5 min. Passage of current through the saline barrel was used to provide $\mathrm{pH}$ and current controls.

Once the control responses were obtained, CAP was injected intradermally using a method similar to that of Simone et al. $(1987,1989)$ but with a higher concentration of CAP. Briefly, $0.1 \mathrm{ml}$ of a solution of $3 \%$ CAP (in Tween 80 and saline) was injected intradermally into the center of the receptive field. The injection produced a skin bleb that was approximately $1 \mathrm{~cm}$ in diameter. In each case, the injection was at least several centimeters from the nearest site chosen for application of the mechanical stimuli and most of the test sites were many centimeters away. The responses of the cell to mechanical and iontophoretic chemical stimulation were then tested beginning $15 \mathrm{~min}$ after injection. In some cases, tests were continued at 60 and 120 min after injection.

Data analysis. The stored digital record of unit activity was retrieved and analyzed off line. Accumulated frequency histograms were generated for all drug-evoked and mechanically evoked events. Background activity averaged over the $2 \mathrm{~min}$ record, and the first $10 \mathrm{sec}$ of each stimulus record was subtracted from all drug-evoked and mechanically evoked events. Differences between responses at the same location and for individual iontophoretic doses were calculated by analysis of variance testing (Student Neuman-Keuls test). Mechanical responses were regarded as significantly changed when the responses to at least two of the five sites were significantly $(p<0.05)$ changed in the same direction (elevation or inhibition). In addition, the total number of spikes evoked by mechanical stimulation following drug application and in the control responses across the entire receptive field was calculated. These total evoked responses were combined for various groups and differences from controls calculated using the Mann-Whitney $U$ test. The responses of a cell to stimulation by EAAs were judged to show a significant effect in response to $\mathrm{CAP}$ when at least two pulse strengths showed a significant $(p<0.05)$ change from baseline in the same direction. The total number of spikes cvoked by chemical stimulation following CAP compared to the control responses was also calculated. Group responses of the STT neurons to chemical stimuli were calculated by obtaining the mean total response for all doses of EAA administered and then combining these values between animals. In addition, averaging the evoked spikes/sec at specific dosages of EAA administered allowed construction of group EAA dose-response curves. All grouped chemically evoked data were tested for statistical significance by the Mann-Whitney $U$ test.

\section{Results}

General observations. Recordings were made from a total of 25 cells in 16 experiments. The neurons included $18 \mathrm{WDR}$ and 7 HT cells. These cells were located from 250 to $1870 \mu \mathrm{m}$ (mean, $1399 \pm 389.6 \mu \mathrm{m}$ ) from the surface of the spinal cord, which corresponds to locations within laminae I-V (Owens, 1991). The latency of the antidromic spikes ranged from $3.07 \mathrm{msec}$ to 
CONTROL

CAPSAICIN

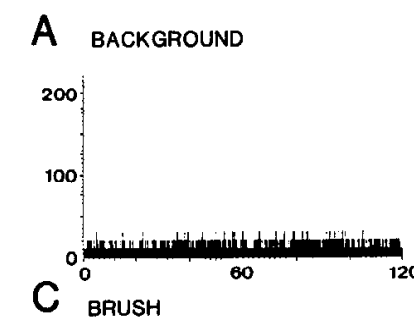

B

0

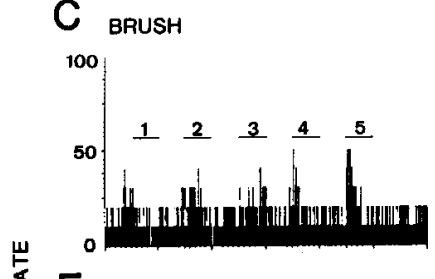

$\underset{\nwarrow}{\stackrel{\varpi}{\leftrightarrows}}$

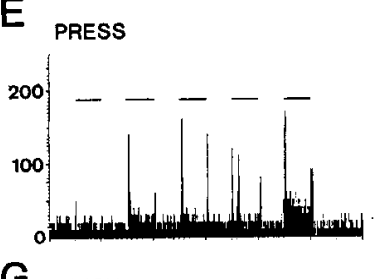

G PINCH

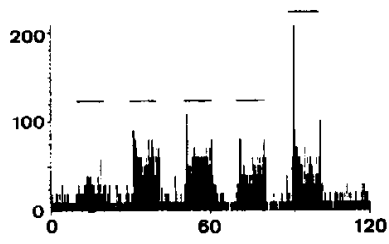

$\mathrm{H}$

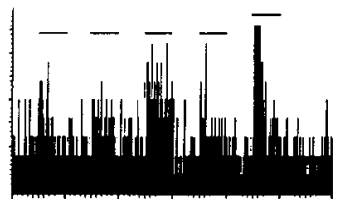

F
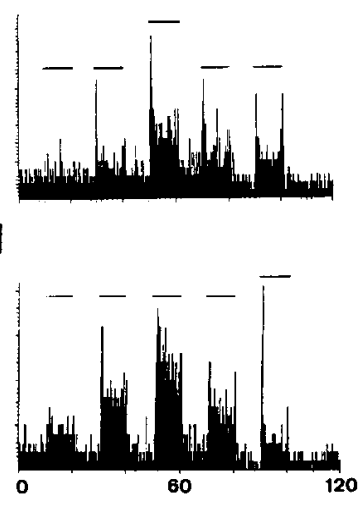

TIME (s)

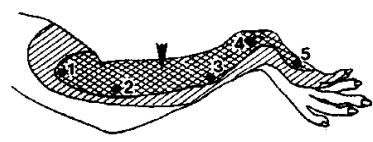

Figure 1. Responses of a WDR STT neuron to mechanical stimulation of the hindlimb before and following intradermal injection of CAP. The control responses for each pair of histograms are on the left, and the responses obtained beginning $15 \mathrm{~min}$ after CAP injection are on the right. The drawing of the leg at the bottom of the figure shows the five points at which the BRUSH, PRESS, and PINCH stimuli were delivered for this cell. The arrowhead indicates the site of CAP injection. The crosshatched area shows the receptive field during the control recording, and the single-hatched area shows the expansion in receptive field induced by the CAP injection. $A$ and $B$ show the background activity of this cell before and then following CAP injection (at arrow). Note the change of time scale in $B$. $C-F$ show the responses to BRUSH and PRESS before and then following CAP. Finally, $G$ and $H$ show the responses to PINCH before and then following CAP.

$17.44 \mathrm{msec}$ (mean, $6.38 \pm 3.28 \mathrm{msec}$ ), and the background activity ranged from 0.05 to 38.3 (mean, $8.32 \pm 8.8$ ) spikes/ sec. The WDR cells were located from $250 \mu \mathrm{m}$ to $1870 \mu \mathrm{m}$ (mean, $1423 \pm 395.8 \mu \mathrm{m}$ ) from the surface of the spinal cord. The latency of the antidromic spikes for the WDR cells ranged from $3.20 \mathrm{msec}$ to $11.57 \mathrm{msec}$ (mean, $5.75 \pm 2.31 \mathrm{msec}$ ). The background activity of the WDR cells ranged from 0.2 to 38.28 spikes/sec (mean, $7.78 \pm 9.35$ spikes/sec). The location of the HT cells ranged from $500 \mu \mathrm{m}$ to $1678 \mu \mathrm{m}$ (mean, $1299.1 \pm$ $400.2 \mu \mathrm{m})$. The antidromic latencies of the HT cells ranged from $3.99 \mathrm{msec}$ to $17.44 \mathrm{msec}$ (mean, $8.02 \pm 5.05 \mathrm{msec}$ ), and the background activity ranged from 2.2 spikes/sec to 23.50 spikes/ sec (mean, $9.71 \pm 8.3$ spikes $/ \mathrm{sec}$ ).

CONTROL
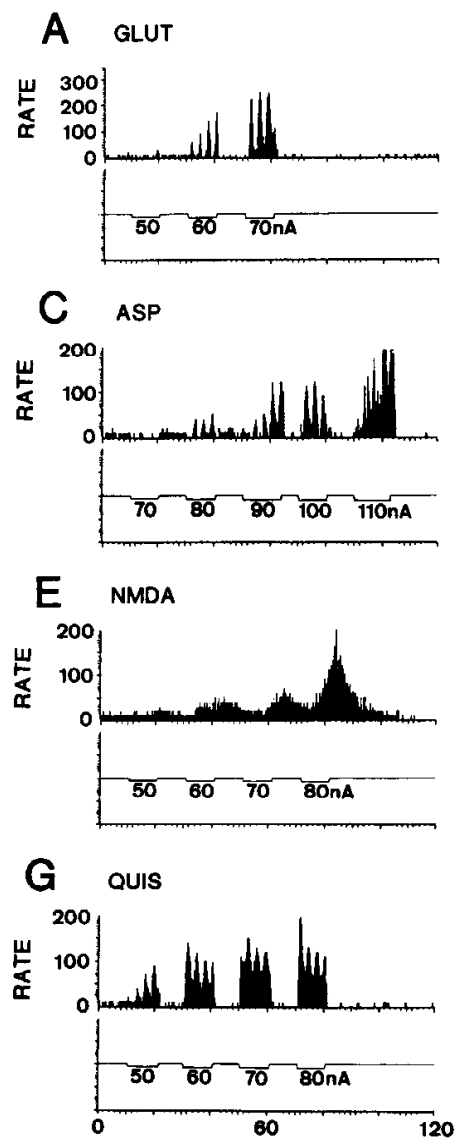

H

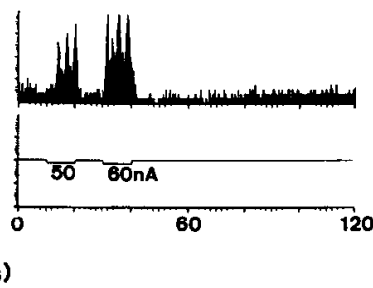

Figure 2. The responses of the same cell illustrated in Figure 1 to four EAAs before and then following CAP. The control recordings for each pair of histograms are at the left, and the recordings obtained after CAP are at the right. A set of recordings showing responses to the endogenous ligands GLUT and ASP are in $A-D$, and responses to the synthetic ligands NMDA and QUIS are in $E-H$. In this one cell, the responses to all EAAs tested were increased following the CAP injection.

Responses of WDR neurons. The sensitization of two represcntative WDR cells is shown in Figures 1-4. The depth of recording of the cell in Figures 1 and 2 was $1362 \mu \mathrm{m}$, and the antidromic latency of this cell was $4.04 \mathrm{msec}$. The depth of recording of the cell in Figures 3 and 4 was $1500 \mu \mathrm{m}$, and the antidromic latency of this cell was $4.8 \mathrm{msec}$. The drawings at the bottom of Figures 1 and 3 show the five sites on the skin from which the responses to BRUSH, PRESS, and PINCH were tested for these cells. The stimulus sites for other cells in the study were similar to these. The background activity of the cells before and after CAP is shown in the top two panels (Figs. $1 A, B$; $3 A, B)$. The needle was inserted into the skin and the resting discharge was allowed to stabilize prior to initiation of the record in $B$. In both cases, it can be seen that the needle insertion caused a small maintained increase in background discharge rates of these cells. Upon injection of CAP (arrows in Figs. $1 B$, $3 B$ ), a very large increase in discharge was immediately observed for both cells. This large increase in activity became somewhat reduced within a few minutes after injection, and the cells assumed a new level of background activity that was substantially higher than in the control recording. 
CONTROL

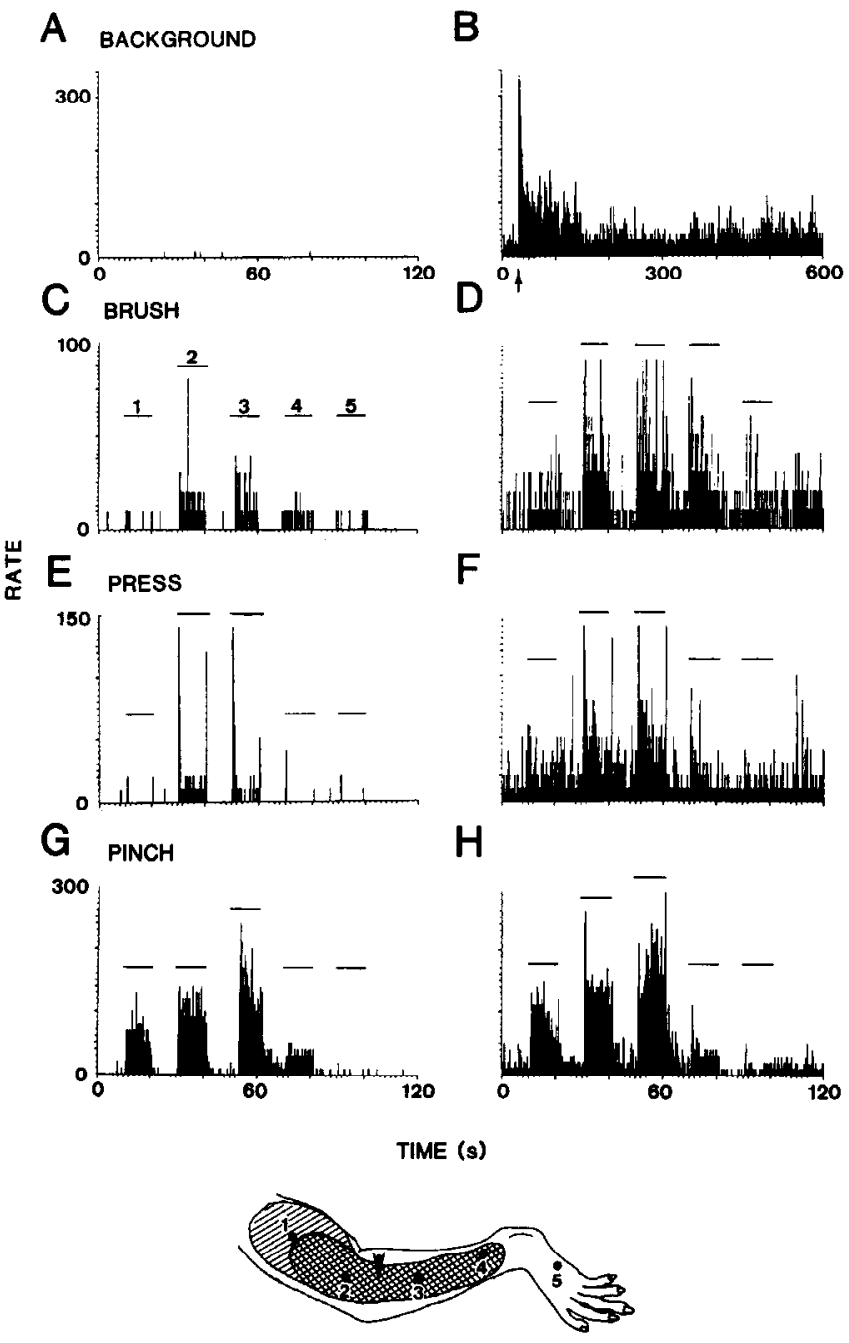

Figure 3. Data from a second representative WDR STT neuron to mechanical stimulation of the hindlimb before and following intradermal injection of capsaicin. The control responses for each pair are on the left, and the responses obtained beginning $15 \mathrm{~min}$ after CAP injection are on the right. The drawing at the bottom of the figure shows the five points at which the BRUSH, PRESS, and PINCH stimuli were delivered for this cell. The arrowhead shows the site at which CAP was injected. The crosshatched area shows the receptive field during the control recording, and the single-hatched area shows the expansion in receptive field induced by the CAP injection. $A$ and $B$ show the background activity of this cell before and then following CAP injection (at arrow). Note the change in time scale in $B$. $C-F$ show the responses to BRUSH and PRESS before and then following CAP. Finally, $G$ and $H$ show the responses to PINCH before and then following CAP.

The responses of these cells to BRUSH, PRESS, and PINCH are shown in the lower panels (Figs. $1 C-H ; 3 C-H$ ). The panels showing the responses to BRUSH ( $C$ and $D$ ) illustrate an increase in mechanoreceptor responses following intradermal CAP. Figure $1 C$ shows that the BRUSH stimulus evoked activity of this cell when applied at sites 2-5. Examination of Figure $3 C$ shows that the other cell had evoked responses that were more readily seen because of the low background activity. At least one of the stimuli evoked responses when applied to test sites 1-4. Following intradermal CAP, the responses to BRUSH were elevated for both cells. Figure $1 D$ shows increased responses at sites 2-5, and there was now also an evoked response to BRUSH
CONTROL
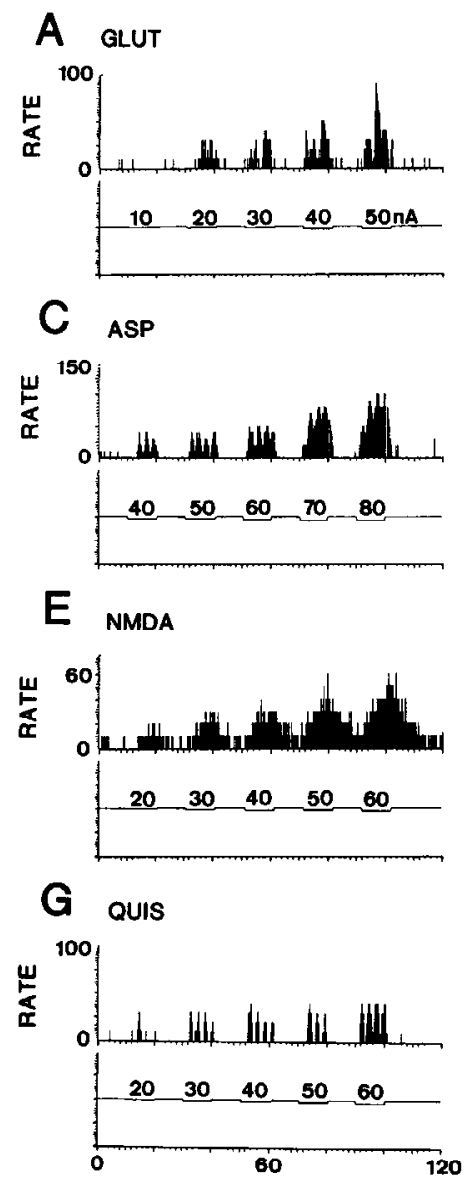

B

CAPSAICIN
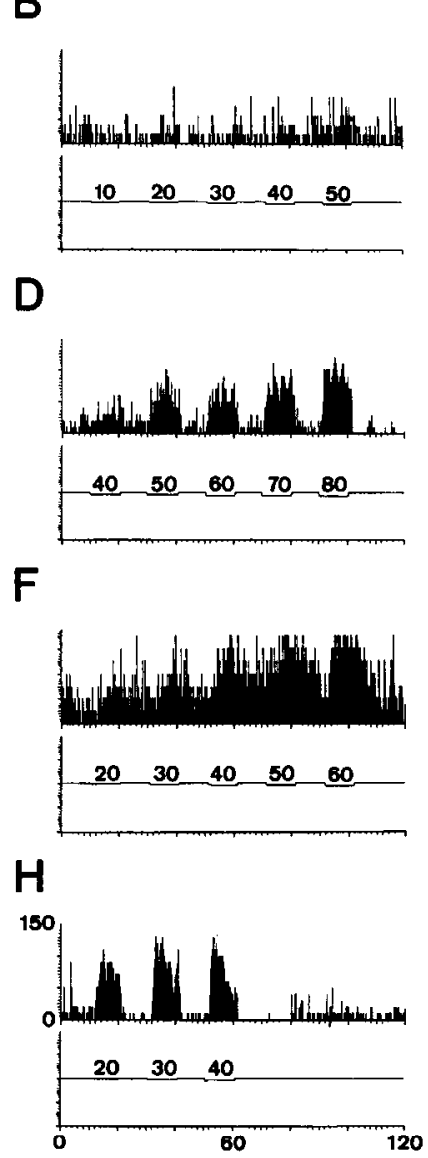

TIME (s)

Figure 4. The responses of the same cell illustrated in Figure 3 to four EAAs before and then following CAP. The control recordings for each pair of histograms are at the left, and the recordings obtained after CAP are at the right. A set of recordings showing responses to the endogenous ligands GLUT and ASP are in $A-D$, and those to the synthetic ligands NMDA and QUIS are in $E-H$. The responses of this neuron to the EAAs following CAP are representative of WDR cells since responses to one ligand of the series, GLUT, showed a reduction while all the others showed an increase after CAP. In all other WDR neurons, responses to at least one ligand showed a reduction or no change while those to others increased.

applied to site 1 . Figure $3 D$ also shows an elevation in responses at sites $1-4$. The initial responses to PRESS (Figs. $1 E, 3 E$ ) were relatively small. Following $C A P$, very prominent responses were obtained from both neurons, best seen in Figure $1 F$ at sites 25 , and in Figure $3 F$ at sites $1-4$. Initially, the first cell responded to $\mathrm{PINCH}$ at all five locations, with the strongest responses at sites 2-5 (Fig. 1G). Following CAP injection, the responses increased, particularly at sites $2-4$, and to a lesser extent at site 1 (Fig. $1 H$ ). The responses at site 5 , in contrast, decreased. The second cell, which was previously responsive to PINCH at sites 1-4 (Fig. 3G), showed an elevation of responses at these sites following CAP without any change in response at site 5 (Fig. $3 H)$.

Figures 2 and 4 show the responses of the same STT cells to iontophoretic application of several EAAs before and after CAP. The responses to the endogenous ligands GLUT and ASP are in $A-D$, and those to the synthetic ligands NMDA and QUIS 


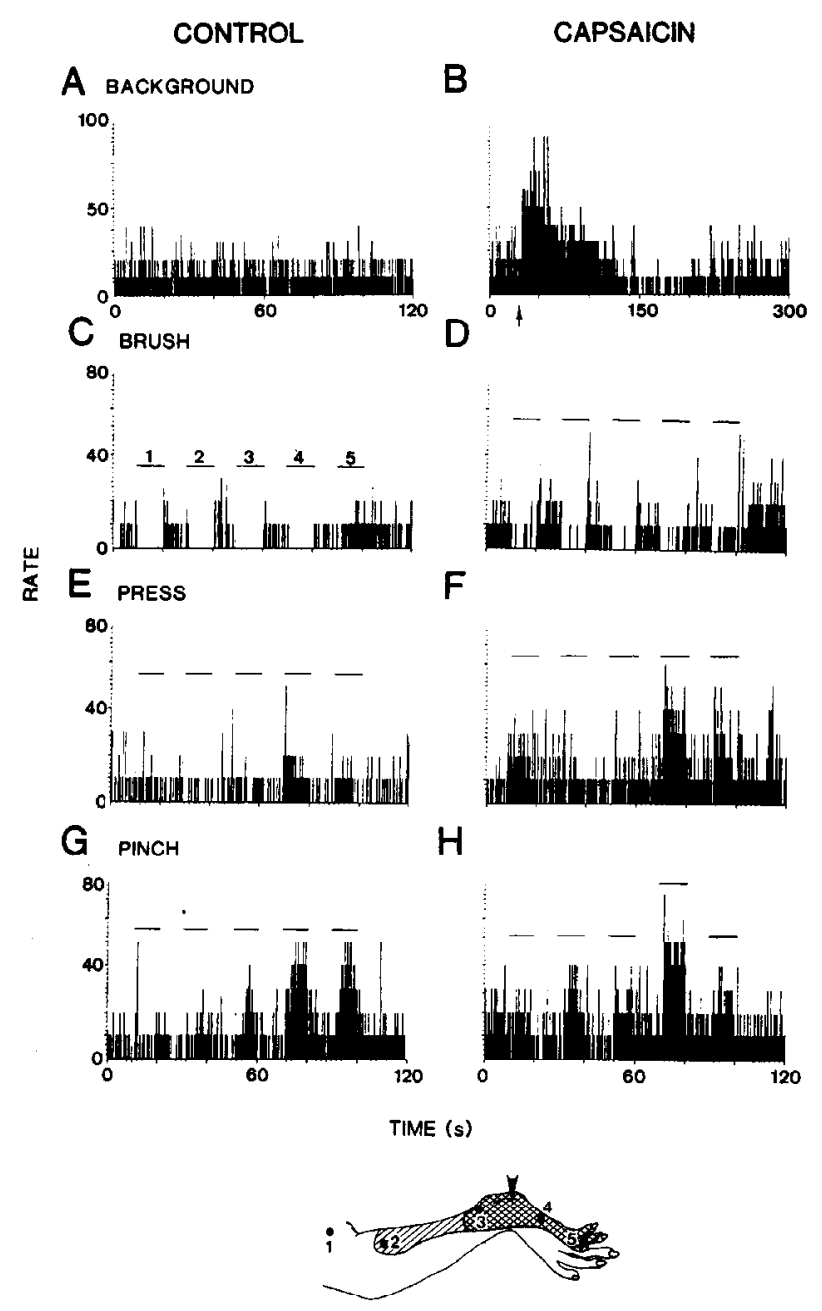

Figure 5. Responses of an HT neuron to mechanical stimulation of the hindlimb before and following intradermal injection of CAP. The control responses for each pair of histograms are on the left, and the responses obtained beginning $15 \mathrm{~min}$ after CAP injection are on the right. The drawing at the bottom of the figure shows the five points at which the BRUSH, PRESS and PINCH stimuli were delivered for this cell. CAP was injected at the site indicated by the arrowhead. The crosshatched area shows the receptive field during the control recording, and the single-hatched area shows the expansion in receptive field induced by the CAP injection. $A$ and $B$ show the background activity of this cell before and then following CAP injection (at arrow). Note the change in time scale in $B$. C-F show the responses to BRUSH and PRESS before and then following CAP; $G$ and $H$ show the responses to PINCH before and then following CAP.

are in $E-H$. The responses of the first cell to all four EAAs were elevated following CAP (Fig. 2). This is best shown for the GLUT responses to 50 and $60 \mathrm{nA}$ pulses, for the ASP responses to the 70-80 nA pulses, for NMDA to the 50-70 nA pulses, and for the QUIS responses to the 50 and $60 \mathrm{nA}$ pulses. As was commonly observed, the apparent threshold for activation of the neurons was lowered and the peak effect was elevated following CAP injection. The second cell (Fig. 4) showed an increase in its responses to ASP, NMDA, and QUIS following CAP, but paradoxically the responses to GLUT were reduced. The pattern of change in EAA responses shown by this WDR cell was representative of that shown by other cells in that for most cells the responses to at least one EAA of the series remained unchanged or showed a reduction. In only one cell did all the EAA responses show an increase.

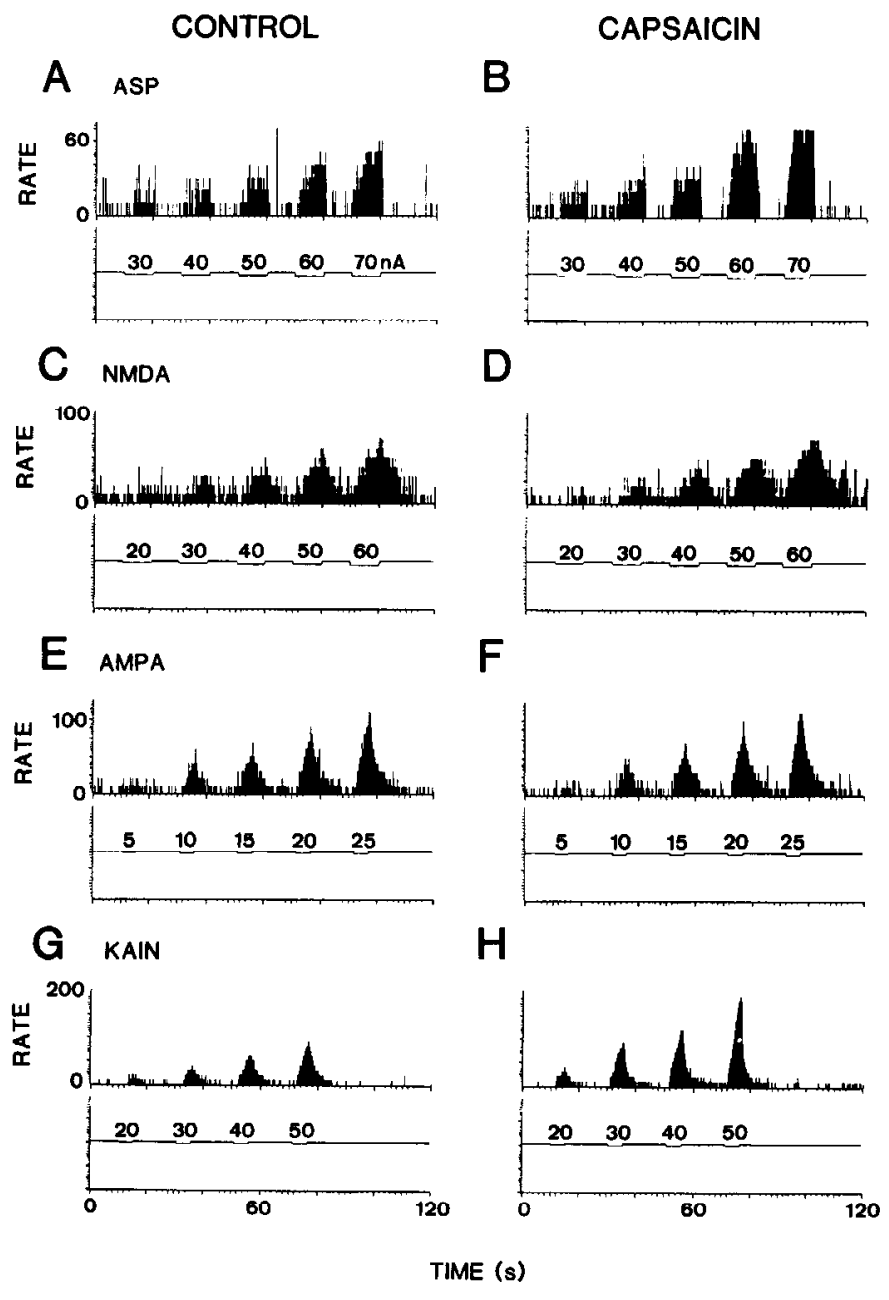

Figure 6. The responses of the same cell illustrated in Figure 5 to four EAAs before and then following CAP. The control recordings for each pair of histograms are at the left and the recordings obtained after CAP are at the right. $A$ and $B$ show the responses to the endogenous ligand ASP, and $C$ and $D$ those to the synthetic ligand NMDA. Responses to AMPA and KAIN are in $E-H$.

Responses of HT neurons. The responses of a representative HT neuron before and after injection of CAP are shown in Figures 5 and 6 . The depth of recording for this cell was 1670 $\mu \mathrm{m}$, and the antidromic latency of this cell was $5.62 \mathrm{msec}$. Figure $5, A$ and $B$, shows that this HT neuron had a moderate rate of background activity prior to the CAP injection. Insertion of the needle into the skin produced a small increase in background discharges of the cell. The discharges of the HT neuron did increase with injection of CAP, but the increase was relatively short lived and was actually followed by a short-lasting decrease in discharge rate below the preinjection level. The cell then resumed a spontaneous discharge rate that was nearly identical to the preinjection rate.

The responses of the HT cell to BRUSH, PRESS, and PINCH before and following CAP are shown in Figure $5 \mathrm{C}-\mathrm{H}$. The discharges of this cell showed a decrease in frequency upon application of the BRUSH stimuli at all five sites in the control recording (Fig. 5C). Following injection of CAP, the inhibition to BRUSH was still evident (Fig. $5 D$ ). A response to PRESS of this neuron was clearly seen in the control recording at site 4, with smaller responses to stimulation at sites 1, 3, and 5 (Fig. 
A

ALL CELLS

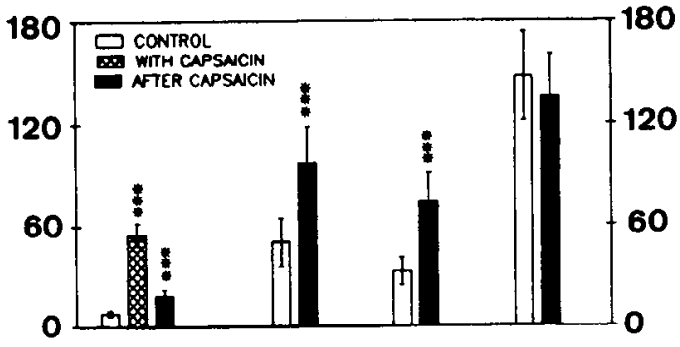

B
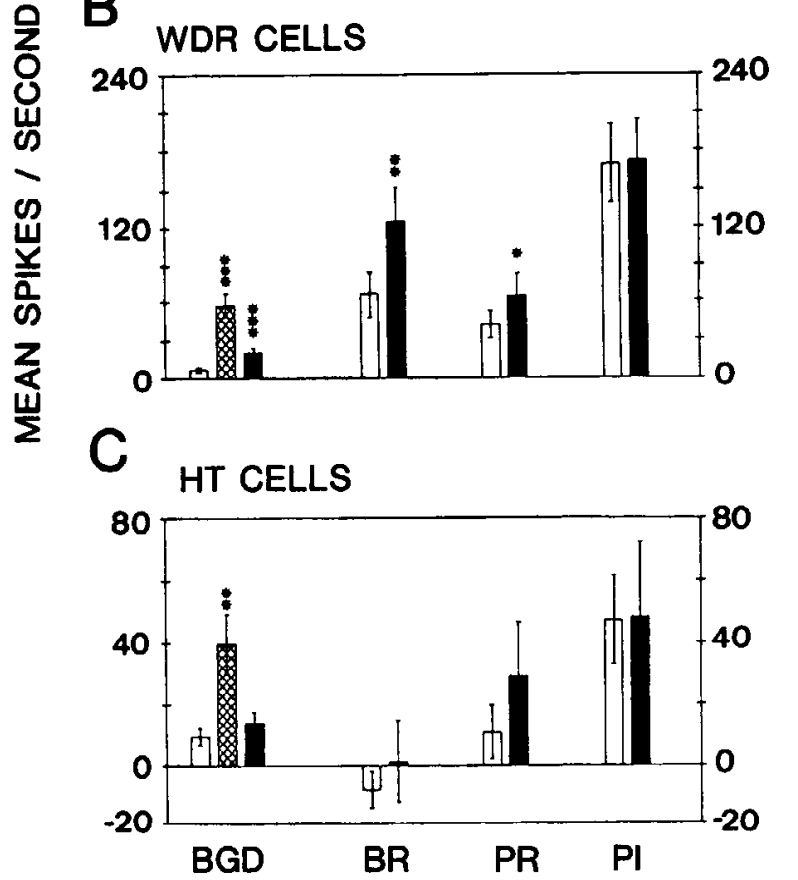

Figure 7. Bar graphs that summarize the grouped data from the STT cells for background activity and for responses to mechanical stimuli. The values in each case are the mean and SE for each group. The lefthand labels on the y-axis apply to the bar graphs for the background activity, and the right-hand y-axis labels apply to the bar graphs for the mechanically evoked responses. $A$ shows data for all STT cells combincd for the effects of CAP on background activity $(B G D)$ and on the sum of the responses to mechanical stimulation $(B R$, BRUSH; $P R$, PRESS; $P I$, PINCH) of all five test sites across the receptive field. The mean background activity was determined by averaging five $10 \mathrm{sec}$ intervals from the baseline record and from the record $15 \mathrm{~min}$ following CAP. The peak in discharge rate was determined by taking the average of the rate for the first $20 \mathrm{sec}$ after injection of CAP. $B$ shows data for the WDR cells, and $C$ the results for the HT cells. In each panel, the control values are the open bars and the post-CAP values are the solid bars. For $B G D$, the crosshatched bars show the rate of discharge of the neurons immediately following injection of CAP. ${ }^{*}, p<0.05 ;{ }^{* *}, p<0.01 ;{ }^{* * *}$, $p<0.001$.

$5 E$ ). Following CAP injection, the responses at site 4 were markedly increased and those at sites 1 and 5 also showed an increase (Fig. $5 F$ ). Responses to PINCH were evoked in the control recording at sites 2-5 (Fig. 5G). Following CAP, the responses to PINCH at sites 2 and 4 showed increases while the responses at the other sites became reduced (Fig. $5 H$ ).

The responses of the same HT cell to iontophoretically applied EAAs before and following CAP are shown in Figure 6. The EAA responses of this cell showed a relatively small change to ASP (Fig. $6 A, B$ ), no change to NMDA or AMPA (Fig. $6 C-F$ ), and a large increase in response to KAIN (Fig. 6G,H). These effects are well seen for ASP at the 50 and $60 \mathrm{nA}$ pulses and for KAIN at all current dosages.

Background activity and the responses to mechanical stimuli. A summary of the effects of CAP injection upon the background activity and responses to mechanical stimuli for the population of cells is shown in Figure 7. Figure $7 A$ shows the results for all cells combined, Figure $7 B$ for the WDR cells, and Figure $7 C$ for the HT cells. The results of the unselected population of cells and the WDR cells were almost identical. The background activity of both categories of cells showed an increase from the control level following intradermal injection of CAP in the receptive fields of the neurons (Fig. 7A,B, bars at left). The peak increase in discharge occurred immediately following injection of CAP, as already shown in the representative examples (Figs. $1 B, 3 B, 5 B$ ). The firing rate of the cells decreased again shortly after the initial large increase and resumed a new baseline rate. As a population, 19 of 25 cells showed a sustained increase in discharge after CAP, 4 cells showed a rate no different than control, and 2 cells showed rates that were lower after CAP than before. Of the 18 WDR cells studied, 16 maintained a background discharge rate after CAP that was higher than the control rate. The two remaining cells resumed a background rate that was not different from control.

When considered as a single population and as WDR cells alone, significant increases in responses to BRUSH and PRESS, but not to PINCH, were observed following intradermal CAP (Fig. 7A,B, three pairs of bars to right). The enhancement of responses to BRUSH and PRESS was evident within $15 \mathrm{~min}$, and the responses remained elevated in some cases for as long as $2 \mathrm{hr}$ following injection of CAP (see Fig. 13). Considering individual cases for both WDR and HT cells, 19 of 24 cells showed an increase in BRUSH response while 2 showed no change and 3 showed a decrease. An increase in BRUSH response following CAP was shown by 15 of 18 WDR neurons; 2 cells showed no change, and 1 cell showed a reduction. The increase in responses of the STT cells to PRESS was nearly as great as that to BRUSH. Fifteen of 19 cells showed an increase, 3 showed no change, and 1 showed a reduction in response to PRESS. An increase in PRESS response was shown by 12 of 13 WDR neurons tested, and a decrease in response was shown by the remaining cell. The responses to PINCH did not significantly change after CAP. Even though almost one-third (7 of 23) of the cells did show an increase in PINCH response after CAP, the number of cells showing a reduction to PINCH after CAP (13) was greater than that showing an increase. This reflects an increase in response of 4 of 16 WDR cells, a decrease in response of 9 cells, and no change in 3 cells.

In many cases, the receptive field area of the WDR cells expanded to incorporate previously nonresponsive areas following the CAP injection. Panels $C$ and $D$ in Figures 1 and 3 show the expansion of receptive field area of the two representative WDR cells for BRUSH (also see drawings in Figures 1 and 3). In some cases, an expansion in receptive field for the responses to PRESS and PINCH was also observed. The expansion of the receptive fields was in both proximal as well as distal directions on the hindlimb. In summary, a total of 15 cells showed an expansion of the receptive field area for BRUSH, 11 showed an expansion of the PRESS receptive field, and only 2 cells showed an expansion of the PINCH receptive field.

The effects of CAP on the background activity and responses to mechanical stimulation of the HT neurons are shown in 
Figure $7 C$ (bars at left). The HT neurons as a group showed a significant increase in discharge rate with injection of CAP. Unlike the WDR neurons, the HT neurons as a group did not show a sustained increase in background activity after the initial increase from the CAP injection so that by $15 \mathrm{~min}$ after CAP the background discharge rate of the HT cells was not significantly above the control level. Three of the seven HT cells did have a sustained increase in background activity, but two cells showed no change from the control spontaneous rate, and two cells showed a reduction in discharge rate. Also unlike the WDR cells, the HT cells as a group showed no significant increases in BRUSH, PRESS, or PINCH evoked activity following CAP. However, the BRUSH response was increased in four cells after CAP, while two cells showed a decrease, and one cell showed no change. The PRESS response increased for three cells (Fig. $5 F$ ) and showed no change in four cells. Two of the three cells that showed an increase in PRESS response also showed an increase in BRUSH response, whereas the other HT cells did not. These cells were determined to have shown an expansion of receptive field area. Finally, the PINCH response increased in three cells (Fig. $5 \mathrm{H}$ ) and decreased in the four remaining cells. In summary, of the seven HT neurons only two showed evidence of sensitization by a sustained increase in background activity and an increase in BRUSH or PRESS after intradermal CAP. Both neurons fulfilling these criteria also showed a decrease in the PINCH response.

Responses to EAAs following CAP. Iontophoretic applications of EAAs were used to evoke responses from all neurons in this study, with two to five EAAs tested on each cell. The responses of the STT neurons to chemical stimulation were grouped by the response profiles of these cells to mechanical stimulation. Neurons were considered as an unselected population, as WDR cells, as HT cells, and as groups that showed sensitization after CAP. A sustained increase in background activity and an increase of the responses to BRUSH and/or PRESS following CAP were used as criteria for cells that showed sensitization. We did not find any cells that were unresponsive to the EAAs applied in a given experiment, although some cells yielded more activity for a particular EAA than another. Responsiveness to a particular EAA type did not significantly correlate with the mechanical responsiveness of the neurons. In addition, all neurons showing an increase in mechanical responses also showed an increase in response to at least one EAA acting upon either NMDA or nonNMDA receptors.

The bar graphs in Figure 8 show the mean total evoked discharges of the STT neurons before and then following CAP. The pair of bars to the right of each panel show the responses for all cells tested. The pair of bars at the left are the responses for those cells showing sensitization. The responses of the STT cells to the non-NMDA EAA agonist QUIS showed the most consistent changes following CAP injection. Figure $8 A$ shows that, following CAP, regardless of changes in background activity and mechanical responses, the population of cells showed a significant elevation in mean total response to QUIS. When only those cells that showed clear evidence of sensitization were considered, the elevation of QUIS responses remained significant. Unlike the responses to QUIS, a statistically significant level of increase in response to AMPA or KAIN was shown only by those cells also showing evidence of sensitization to mechanical stimulation (bars on the left side of Fig. $8 B, C$ ). In the case of NMDA, however, the increase in responses to the EAA was observed only in those sensitized neurons that were not exposed
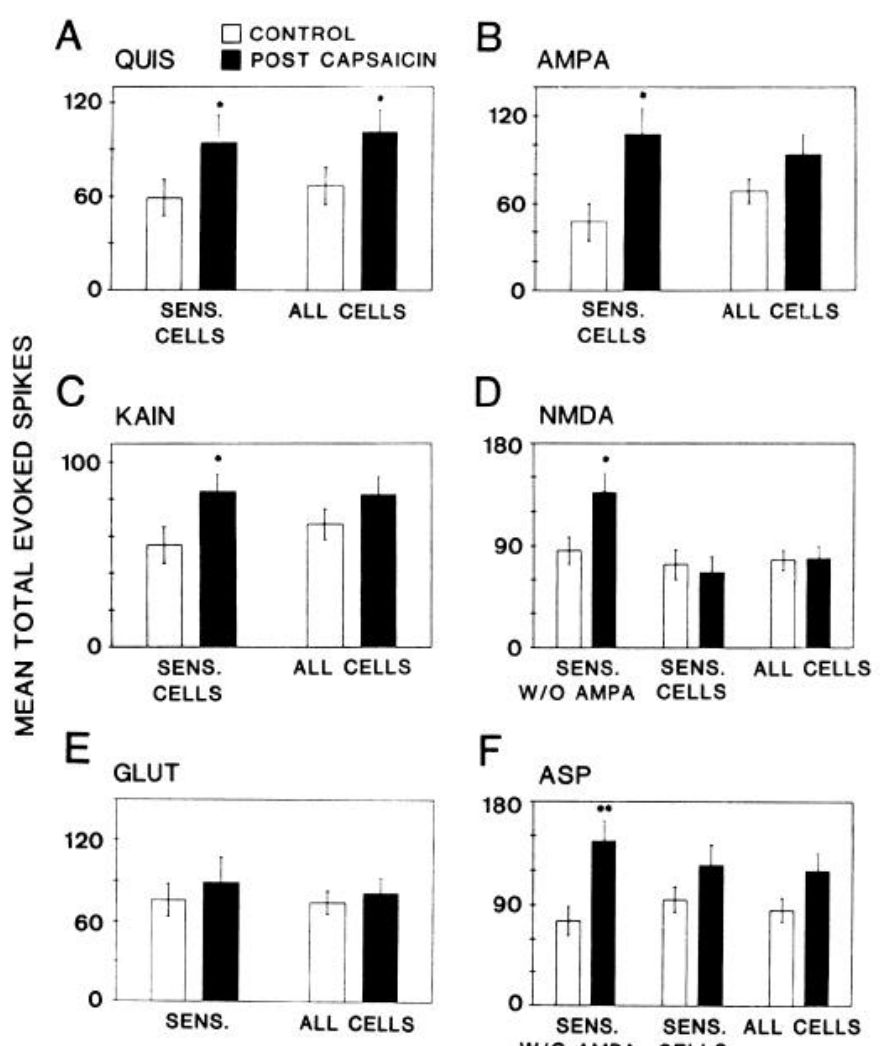

F

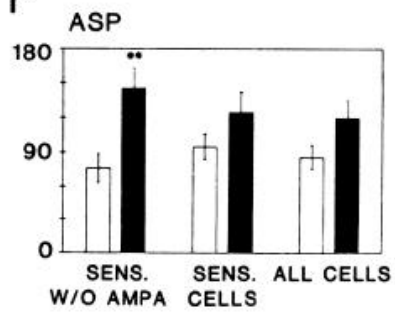

Figure 8. Bar graphs summarizing the mean total spikes (and SE) evoked by each of the EAA ligands before and then following CAP. In each panel, the open bars are the control values and the solid bars are the values obtained after CAP. In each panel for the non-NMDA ligands and GLUT $(A-C, E)$, the right pair of bars are the data for all cells tested and the left pair of bars shows data only for those cells showing evidence of sensitization by CAP. In the case of NMDA and ASP ( $D$ and $F$ ), the values for all cells appear at the far right as in the other panels, but the data showing evidence of sensitization are presented in two ways. The center pair of bars shows the data for all sensitized cells, and the left pair of bars shows the data for those sensitized cells that were not exposed to AMPA. ${ }^{*}, p<0.05 ;{ }^{* *}, p<0.01$.

to AMPA (Fig. $8 D$ ). The responses of the STT cells to ASP and GLUT, although also showing a tendency to increase after CAP injection, did not show a statistically significant level of increase for all cells or the sensitized group. When the sensitized ASP cells were further subdivided into cells that were not exposed to AMPA, a statistically significant increase was observed. For GLUT, there was no statistically significant increase in the grouped responses regardless of exposure to AMPA.

Figure 9 shows the number of EAAs for which responses increased in cells sensitized by injection of CAP. Considered as a single population, it was most commonly observed that the responses to two or three EAAs would increase following sensitization of the neurons with CAP. In some cases, the responses to only a single EAA showed an elevation, and in others the responses to up to four EAAs showed an increase. When the population was divided into WDR and HT cells, it was observed that the WDR cells had the same general characteristics as the total population. Most sensitized WDR cells showed an increase in responses to two or three EAAs. Sensitized HT cells tended to have increases in responses to several EAAs after CAP; however, this cell group was small.

The bar graphs in Figure 10 show the number of sensitized 


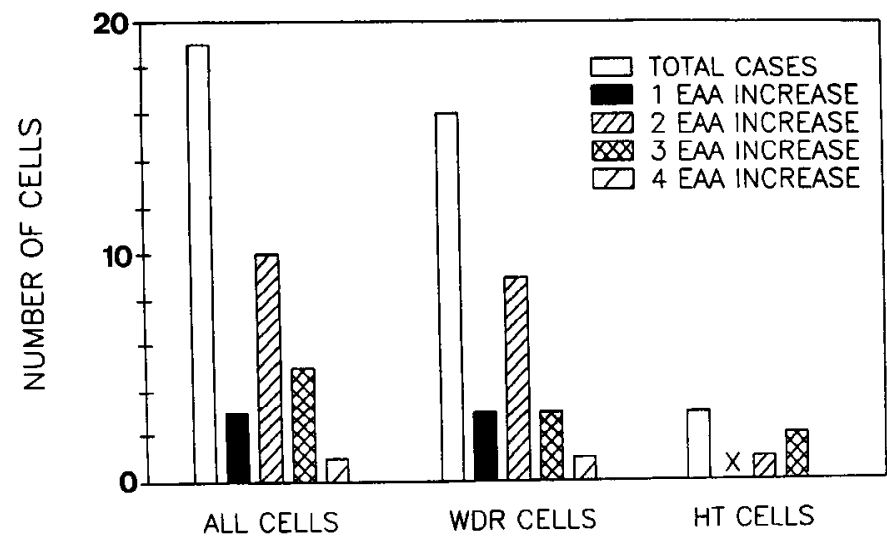

Figure 9. Bar graphs summarizing the frequency distribution of the number of cells showing sensitization following intradermal CAP (open bars), and the number of EAAs for which there was an increase in response after CAP for these sensitized cells. The distribution for the whole cell population is at left, for the WDR cells is in the center, and for the HT cells is at the right. $X$, No observations.

neurons tested with each EAA and the direction of change in response after CAP. The results for each EAA are shown as an unselected population and as cells divided into WDR and HT groups. In each case, the results for the unselected population and the WDR cells were very similar due to the large proportion of WDR cclls in our sample. CAP mainly caused an increase in the number of discharges evoked by each EAA. However, for each EAA it was found that in some cases the responses were reduced or remained unchanged after CAP.

The averaged dose-response curves for each of the EAAs before and then $15 \mathrm{~min}$ following CAP are shown in Figure 11 for those cells showing evidence of sensitization. The curves of the responses to each of the EAAs showed a leftward shift at each current dosage for those neurons showing a statistically significant sensitization of response to mechanical stimulation. The responses to most of the post-CAP dosages achieved a statistically significant increase for all EAAs except GLUT (Fig. 11).
Relationship between $E A A$ responses. The bar graphs in Figure 12 show the relationships of changes in responses observed between EAAs. In each panel, the responses to one EAA is used as a reference. The open bars within that panel show the number of sensitized cells tested for the reference EAA (open bar, left cluster) as well as the number of changes that were increases (open bar, center cluster) or decreases (open bar, right cluster) from control. The number of cases in which other EAAs were tested and the cases in which these other EAAs showed the same direction of change as the reference EAA are also shown. It was observed that changes in responses to QUIS and NMDA and those to NMDA and ASP were often in the same direction for a particular cell. The changes in responses to QUIS and ASP did not often show parallel changes, most likely because both were seldom tested in the same cells. The responses to ASP and GLUT frequently showed similar changes, whereas those to GLUT and NMDA did not. However, the changes in responses to NMDA and AMPA, and to a lesser extent to ASP and AMPA, were inversely related, so that as the response to one EAA increased, that to the other showed either no change or a decrease.

Time course of changes in mechanical and EAA responses. The time courses of the changes in responses of five WDR cells were followed beyond the initial post-CAP testing period. Two cells were followed for $2 \mathrm{hr}$ after the CAP injection. One of these was the WDR cell illustrated in Figures 1 and 2, and the other was the WDR cell illustrated in Figures 3 and 4. The time courses of the responses of these cells are shown in Figurc 13. The background activity and the responses to all three mechanical stimuli were elevated within $15 \mathrm{~min}$ following the CAP injection (Fig. 13A,C). The responses had begun to decrease at $1 \mathrm{hr}$ after CAP, although they still remained elevated compared to the control levels. By $2 \mathrm{hr}$ after CAP, the background activity had returned essentially to the original level. The responses to at least some of the mechanical stimuli remained elevated. Figure $13, B$ and $D$, shows the time course of the EAA responses of these same cells. The first cell showed an increase of response to all four EAAs that paralleled the increase in mechanical responsiveness of this cell. The second WDR cell showed an increase in responses to QUIS, NMDA, and ASP, while the re-
Figure 10. Bar graphs summarizing the number of sensitized cells tested with each EAA (open bars), and the direction of change in EAA response shown by these cells. For each amino acid, the data for the whole population are in the leftmost cluster of bars, the data for the WDR cells are in the center cluster of bars, and the data for the HT cells are in the right hand cluster of bars. $X$, no observations.

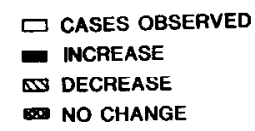

QUIS
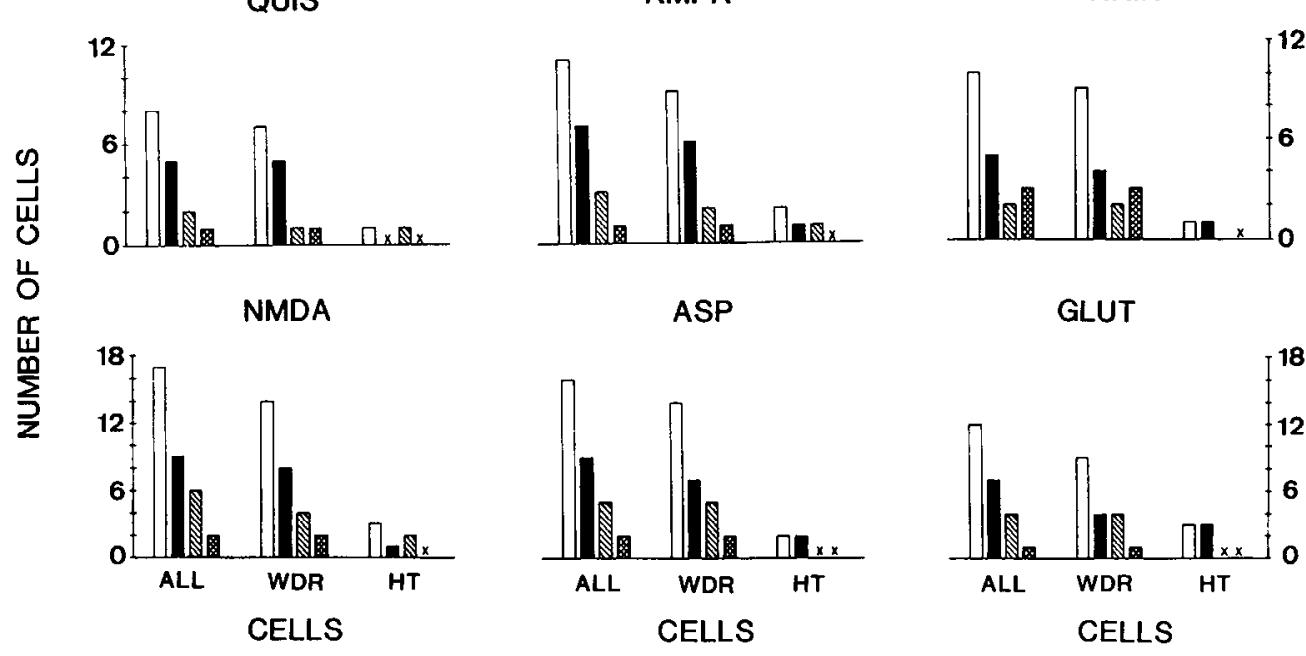

GLUT

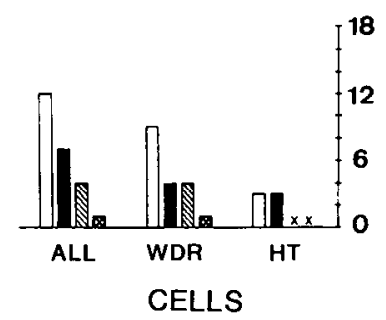


A
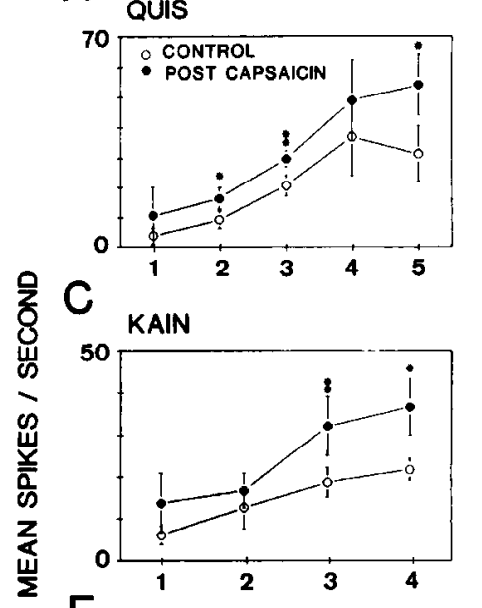

E GLUT

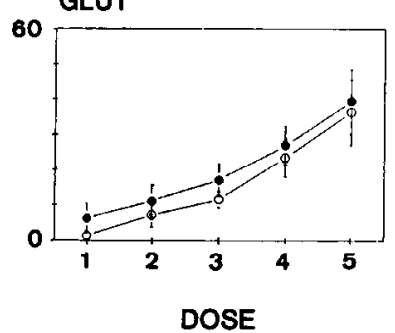

$B$

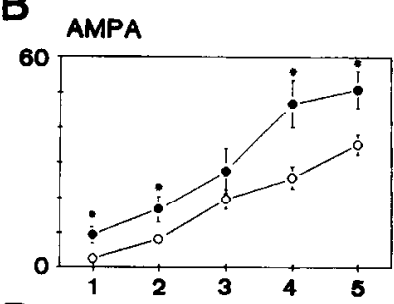

D

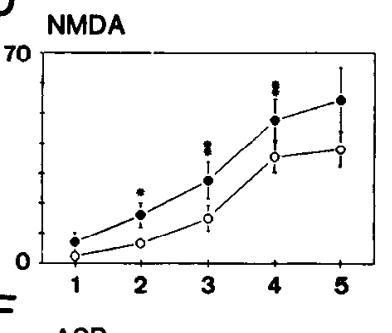

$F$

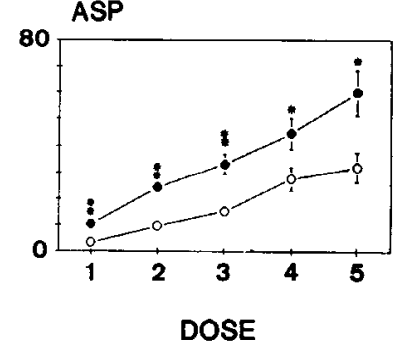

Figure 11. Summary of the mean dose-response curves for the synthetic ligands before and then $15 \mathrm{~min}$ following intradermal injection of capsaicin. For the non-NMDA ligands $(A-C, E)$, the curves were made from responses to cells showing evidence of sensitization. For NMDA and ASP $(D$ and $F)$, the data for the curves were drawn only from sensitized cells that were not exposed to AMPA. *, $p<0.05 ;{ }^{* *}$, $p<0.01$.

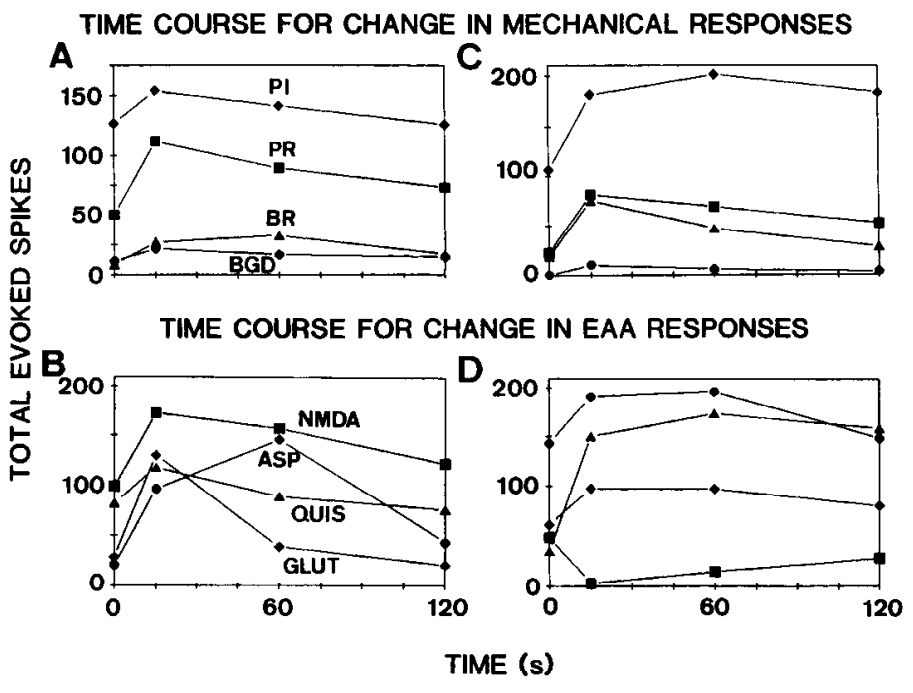

Figure 13. Line graphs showing the time course of changes in responses to mechanical and chemical stimulation of two WDR cells. $A$ shows the time course of the change shown by the cell illustrated in Figures 1 and 2 in background activity $(B G D)$ and in responses to the mechanical stimuli (BR, BRUSH; PI, PINCH; PR, PRESS). $B$ shows the time course of the changes in responses of this cell to the endogenous ligands, GLUT and ASP, and the synthetic ligands, NMDA and QUIS. $C$ and $D$ show changes in responses to mechanical stimulation and EAAs for the cell used for Figures 3 and 4.

sponse to GLUT decreased, again with a time course similar to that of the changes in responses to mechanical stimulation.

\section{Discussion}

CAP is of particular interest as a neurotoxin that specifically destroys unmyelinated primary afferent fibers (Jansco and Kiraly, 1980; McMahon et al., 1984; Russell and Burchiel, 1984;
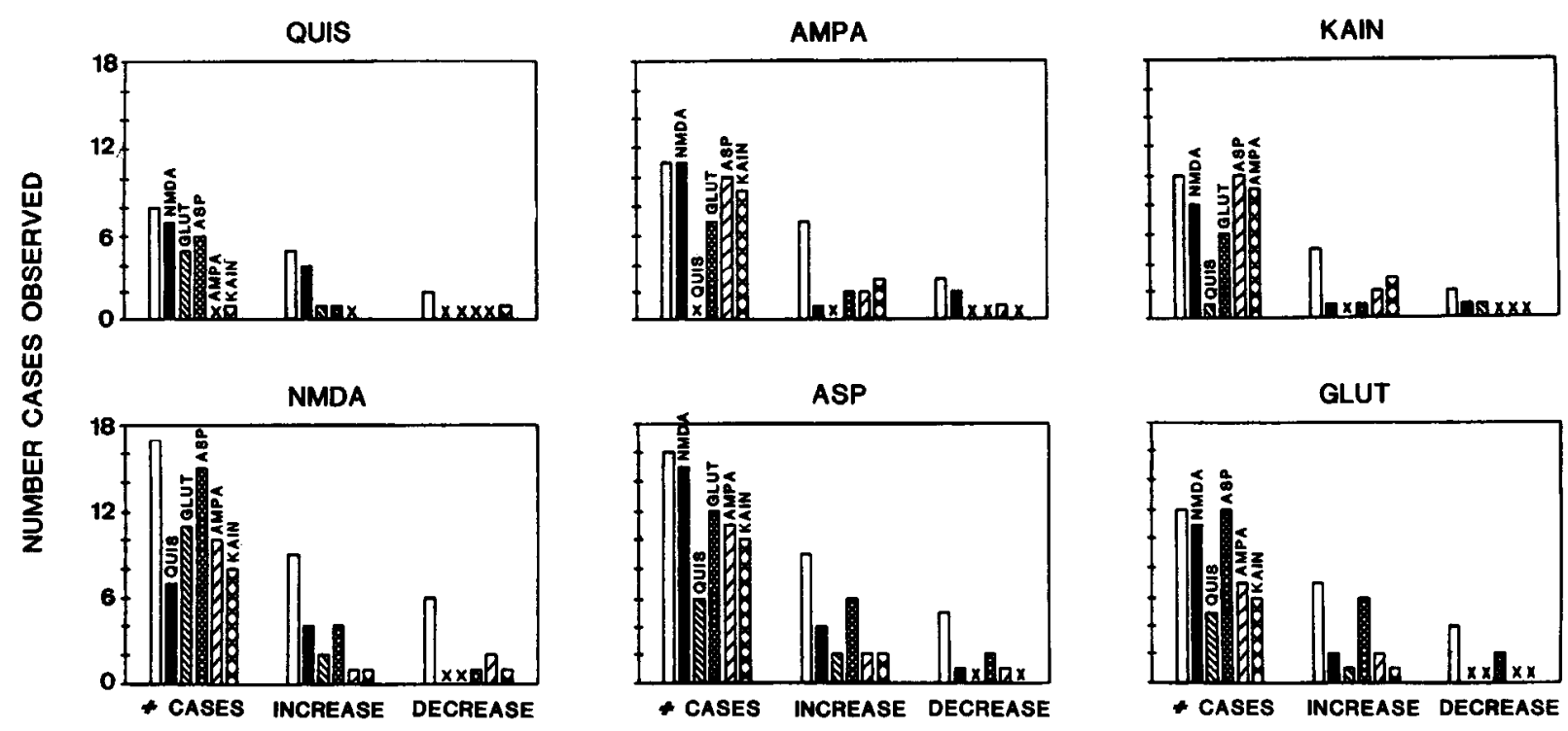

Figure 12. Bar graphs summarizing the relationships in response changes for each EAA. The EAA labeled at the top of each panel is used as the reference for that panel. The open bars show the number of sensitized cells tested with that EAA (left), the number of cases in which the response for the reference was increased (center), and the number of cases in which the response was decreased (right). The remaining bars in each panel are labeled to show the number of other EAAs tested for those in which the reference EAA was tested, and the number of times an increase or decrease in response was shared with the reference EAA. $X$, no observations. 
Chung et al., 1985). Initial studies using CAP showed that systemic administration to neonatal rats resulted in loss of most or all unmyelinated afferent fibers and some A $\delta$ fibers. More recently, $\mathrm{C} \Lambda \mathrm{P}$ has been used as an inflammatory substance administered topically or intradermally (Simone et al., 1989, 1991; McMahon et al., 1991). CAP causes an initial excitation of unmyelinated primary afferent nociceptive fibers (Jansco and Kiraly, 1980; Russell and Burchiel, 1984; Baumann et al., 1991). Since these small fibers affected by CAP contain neuropeptides, such as SP and CGRP, and EAA neurotransmitters (Hokfelt et al., 1975; DeBiasi and Rustioni, 1988; McNeill et al., 1989; Westlund et al., 1989, 1990b), it is expected that all of these substances would be released both in the periphery as well as in the spinal cord upon administration of CAP. Such an effect of CAP upon SP release has been demonstrated both in vivo and in vitro (Olgart et al., 1977; Gamse et al., 1979, 1981; Theriault et al., 1979). This bidirectional release of transmitters may help produce sensitization of peripheral afferent fibers (Louis et al., 1989), resulting in primary hyperalgesia, as well as a sensitization of spinal cord neurons, resulting in a secondary hyperalgesia (Simone et al., 1989, 1991; Dougherty and Willis, 1991). Both types of hyperalgesia produced by CAP are correlated with changes in the discharge properties of STT neurons in monkeys (Simone et al., 1991) and are observed in psychophysical testing of human subjects (LaMotte et al., 1991). Of particular interest in this model of hyperalgesia is the development of a hypersensitivity to weak mechanical stimuli following stimulation of nociceptive C-fiber afferents, corresponding to the induction of allodynia.

Our results confirm the findings of Simone et al. (1991) that intradermal CAP causes excitation of STT cells followed by a sensitization of these neurons to mechanical stimuli, including input from sensitive mechanoreceptors. The time course of the observed changes in background activity and responses to mechanical stimulation immediately following CAP injection (Fig. 13) was comparable to that reported by human subjects for spontaneous pain and increased sensitivity of the skin surrounding the injection site (LaMotte et al., 1991). We also found that the effects of CAP were different for the subpopulations of WDR and HT STT neurons, as previously observed by Simone et al. (1991). Both classes of neuron discharged vigorously immediately after the injection of CAP into the skin, but only the WDR STT cells continued to discharge at a rate substantially above the initial background level for an extended period of time. This suggests that both types of STT neurons contribute to the intense pain experienced just after intradermal CAP injection in humans (LaMotte et al., 1991), but that only the WDR cells are likely to be responsible for the maintained pain. The duration of the increased firing rate of the STT cells in the present study was longer than that observed by Simone et al. (1991), presumably because of the higher dose of CAP used. However, the previous study did not examine the time course of the changes in background activity or in responses to innocuous and noxious mechanical stimuli in detail. Another difference in the behavior of WDR and HT STT cells following CAP injection was that there was a significant increase in the mean BRUSH and PRESS responses of the WDR but not of HT cells. Although occasional HT cells do show increased responses to mechanical stimuli, in general WDR cells are likely to play a greater role in the development of secondary hyperalgesia and allodynia following chemical damage to the skin.

Our results indicate that an increase in responses of STT neurons to iontophoretically applied EAAs occurs following CAP injection. The increases in responses included those to EAAs acting upon both NMDA and non-NMDA receptors, and the timc course of the increase in EAA responses paralleled the increases in background activity and responsiveness to mechanical stimulation. Thus, our results support the conclusion that CAP induces hyperalgesia with allodynia through sensitization of WDR and some HT sensory projection neurons (LaMotte et al., 1991; Simone et al., 1991). More generally, our results support a role for EAAs in the transmission of nociceplive information in the spinal cord as proposed previously (Davies and Watkins, 1983; Salt and Hill, 1983; Schneider and Perl, 1985; Aanonsen and Wilcox, 1987; Davies and Lodge, 1987; Aanonsen et al., 1990; Dickenson and Sullivan, 1990; Wilcox, 1991; Dougherty and Willis, 1991).

Our findings are consistent with the proposal that a potentiation of EAA responses by corelease of peptides contributes to the hyperalgesia associated with peripheral injury. We have previously shown that coapplication of an EAA with SP will result in a potentiation of responses to later applications of that EAA, as well as an increase in the activity evoked by mechanical stimulation of the receptive field (Dougherty and Willis, 1991). A similar observation of potentiation of EAA responsiveness by combined application with SP has also been shown using in vitro preparations (Gu and Huang, 1989; Randic et al., 1990). Moreover, an increase in responsiveness of STT neurons to EAAs following the induction of an experimental arthritis is accompanied by an increase in responsiveness to mechanical stimulation (Dougherty et al., in press), and peptides are known to be released in the dorsal horn during the development of experimental arthritis (Schaible et al., 1990). Since administration of CAP is known to cause release of SP into the dorsal horn of the spinal cord (Gamse et al., 1979), it is likely that a potentiation such as that produced by iontophoretic coapplication of EAAs and peptides may underlie the potentiation of EAA responscs obscrved in the present study.

The present study revealed two characteristics of the responses of sensitized STT cells to EAAs that we have not previously noted. First, we often saw an increase in responses to more than one EAA after the CAP injection. In our previous studies, enhancement of responses has been specific to either NMDA or non-NMDA ligands but not both simultaneously (Dougherty and Willis, 1991; Dougherty et al., in press). We hypothesize that in this particular model of hyperalgesia, one of two possibilities explains the more generalized increase in EAA responses. The first possibility is that the CAP injection produces a much greater afferent barrage into the spinal cord, which results in a greater degree of initial or sustained depolarization of the STT cells and adjacent interneurons. Alternatively, multiple neuromodulators may be released by the C-fibers activated by CAP, and these in turn are able to enhance the responses to morc than one EAA type at a time. Candidates in addition to SP that may increase responses to EAAs include CGRP and other neuropeptides that are known to play a role in other models of hyperalgesia, such as the enhancement of flexion reflexes by electrical stimulation of C-fibers (WiesenfeldHallin et al., 1989; Woolf and Thompson, 1991). Both possibilities suggest that activation of separate second messenger systems results in enhancement of responses to different EAA subtypes. Our finding that the grouped responses to BRUSH and PRESS are increased in preference to the responses to PINCH seems to be in conflict with either of these possibilities, yet in 
some cases a uniform enhancement of responses to all mechanical stimuli was observed (see Figs. 1, 3, 13). The lack of a uniform increase in PINCH for all animals may be due to a selective influence of descending controls, cxpected to be activated by the C-fibers stimulated by CAP, upon high-threshold versus low-threshold inputs (Zhang et al., 1991). Alternatively, the responses to PINCH may have been too near the maximal rate of discharge of some neurons to show any further significant increase.

The second observation of note in the present work is that there appears to be a negative interaction between EAAs acting upon NMDA receptors and the AMPA type of non-NMDA receptors. In many sensitized cells, an inverse relationship between changes in responses to NMDA and to AMPA was noted. As the response to one EAA increased, the response to the other decreased or remained unchanged. This type of regulation would not be without precedent, since a negative interaction between the responses to various EAA agonists has been shown in three in vitro preparations: dissociated chick spinal cord, cultures of rctinal horizontal cclls, and slicc prcparations of the hippocampus in rats and mice (Ishida and Neyton, 1985; Vlachova et al., 1987; Palmer et al., 1988; MacDonald et al., 1989). Such a regulation, if present in the monkey spinal cord, might help explain our difficulty in showing significant changes in the grouped EAA responses to the endogenous ligands ASP and GLUT, since the action of these ligands upon spinal neuron discharges is mixed on both NMDA and non-NMDA receptors (Watkins and Evans, 1981).

In conclusion, the present study has demonstrated that increased responses of STT neurons to mechanical stimulation, including those to BRUSH and PRESS stimuli, may be produced by intradermal injections of the neurotoxin CAP; this is consistent with previous reports (Simone et al., 1989, 1991). In addition, the increase in responsiveness to mechanical stimulation is accompanied by an increase in the responses of STT ncurons to EAAs, often acting at both NMDA and non-NMDA receptors. These results support the hypothesis that an enhancement of the responses of spinal cord neurons, including STT cells, to EAAs released by primary afferent stimulation may lead to the generation of hyperalgesia and allodynia.

\section{References}

Aanonsen LM, Wilcox GL (1987) Nociceptive action of excitatory amino acids in the mouse: effects of spinally administered opioids, phencyclidine and sigma agonists. J Pharmacol Exp Ther 243:9-19.

Aanonsen LM, Lei S, Wilcox GL (1990) Excitatory amino acid receptors and nociceptive neurotransmission in rat spinal cord. Pain 41:309-321.

Baumann TK, Simone DA, Shain CN, LaMotte RH (1991) Neurogenic hyperalgesia: the search for the primary cutaneous afferent fibers that contribute to capsaicin-induced pain and hyperalgesia. J Neurophysiol 66:212-227.

Boivie J, Leijon G, Johansson I (1989) I. Central post-stroke paina study of the mechanisms through analysis of the sensory abnormalities. Pain 37:173-185.

Carlton SM, LaMotte CC, Honda CN, Surmeier DJ, DeLanerolle NC Willis WD (1985) Ultrastructural analysis of substance P and other synaptic profiles innervating an identified primate spinothalamic tract neuron. Soc Neurosci Abstr 11:578.

Carlton SM, Westlund KN, Zhang D, Sorkin LS, Willis WD (1990) Calcitonin gene-related peptide containing primary afferent fibers synapse on primate spinothalamic tract cells. Neurosci Lett 109:7681 .

Chung JM, Lee KH, Hori Y, Willis WD (1985) Effects of capsaicin applied to a peripheral nerve on the responses of primate spinothalamic tract cells. Brain Res 329:27-38.
Davies J, Watkins JC (1983) Role of excitatory amino acid receptors in mono- and polysynaptic excitation in the cat spinal cord. Exp Brain Res 49:280-290.

Davies SN, Lodge D (1987) Evidence for involvement of $N$-methylaspartate receptors in "wind-up" of class 2 neurons in the dorsal horn of the rat. Brain Res 424:402-406.

DeBiasi S, Rustioni A (1988) Glutamate and substance P coexist in primary afferent terminals in superficial laminae of spinal cord. Proc Nat Acad Sci USA 85:7820-7824.

Dickenson AH, Sullivan AF (1990) Differential effects of excitatory amino acid antagonists on dorsal horn nociceptive neurones in the rat. Brain Res 506:31-39.

Dougherty PM, Willis WD (1991) Enhancement of spinothalamic neuron responses to chemical and mechanical stimuli following combined microiontophoretic application of $N$-methyl-D-aspartic acid and substance P. Pain 47:85-93.

Dougherty PM, Sluka KA, Sorkin LS, Westlund KN, Willis WD (in press) Enhanced responses of spinothalamic tract neurons to excitatory amino acids parallel the generation of acute arthritis in the monkey. Brain Res Rev, in press.

Ferrington DG, Sorkin LS, Willis WD Jr (1987) Responses of spinothalamic tract cells in the superficial dorsal horn of the primate lumbar spinal cord. J Physiol (Lond) 388:681-703.

Gamse R, Molnar A, Lembeck F (1979) Substance P release from spinal cord slices by capsaicin. Life Sci 25:629-636.

Gamse R, Lackner D, Gamse S, Leeman SE (1981) Effect of capsaicin pretreatment on capsaicin-cvoked relcase of immunorcactive somatostatin and substance $P$ from primary sensory neurons. NaunynSchmiedeberg's Arch Pharmacol 316:38-41.

Gu Y-P, Huang L-YM (1989) Effects of excitatory amino acids on neurons isolated from spinal trigeminal nuclei. Soc Neurosci Abstr 15:947.

Handwerker HO, Holzer-Petsche U, Heym C, Welk E (1984) C-fibre functions after topical application of capsaicin to a peripheral nerve and after neonatal capsaicin treatment. In: 29th IUPS, satellite symposium (Chahl LA, Szolcsanyi J, Lembeck F, eds), pp. 57-82. Budapest: Akademiai Kiado.

Handwerker H, Kilo S, Reeh PW (1991) Unresponsive afferent nerve fibres in the sural nerve of the rat. J Physiol (Lond) 435:229-242.

Hardy JD, Wolff HG, Goodell H (1952) Pain sensations and reactions. Reprint. New York: Hafner, 1967.

Hokfelt T, Kellerth JO, Nilsson G, Pernow B (1975) Substance P: localization in the central nervous system and in some primary sensory neurons. Science 190:889-890.

Ishida AT, Neyton J (1985) Quisqualate and L-glutamate inhibit retinal horizontal-ccll responses to kainate. Proc Nat Acad Sci USA 82: 1837-1841.

Jansco G, Kiraly E (1980) Distribution of chemosensitive primary sensory afferents in the central nervous system of the rat. J Comp Neurol 190:781-792.

Kenshalo DR Jr, Leonard RB, Chung JM, Willis WD (1979) Responses of primate spinothalamic neurons to graded and to repeated noxious heat stimuli. J Neurophysiol 42:1370-1389.

Kenshalo DR Jr, Leonard RB, Chung JM, Willis WD (1982) Facilitation of the responses of primate spinothalamic cells to cold and to tactile stimuli by noxious heating of the skin. Pain 12:141-152.

LaMotte RH, Shain CN, Simone DA, Tsai E-FP (1991) Ncurogenic hyperalgesia: psychophysical studies of underlying mechanisms. J Neurophysiol 66:190-211.

Lewis T (1942) Pain. London: Macmillan.

Liu D, Sorkin LS, Hughes MG, McAdoo DJ (1989) Release of aspartate and glutamate in the dorsal horn of the cat lumbar spinal cord in response to intradermal capsaicin injection. Soc Neurosci Abstr 15:549.

Louis SM, Jamieson A, Russell NJW, Dockray GJ (1989) The role of substance $P$ and calcitonin gene-related peptide in neurogenic plasma extravasation and vasodilatation in the rat. Neuroscience 32:581586

Lynn B, Shakhanbeh J (1988) Substance P content of the skin, neurogenic inflammation and numbers of $\mathrm{C}$-fibres following capsaicin application to a cutaneous nerve in the rabbit. Ncuroscience 24:769775 .

MacDonald JF, Mody I, Salter MW (1989) Regulation of $N$-methylD-aspartate receptors revealed by intracellular dialysis of murine neurones in culture. J Physiol (Lond) 414:17-34. 
McMahon SB, Wall PD, Granum SL, Webster KE (1984) The effects of capsaicin applied to peripheral nerves on responses of a group of lamina I cells in adult rats. J Comp Neurol 227:393-400.

McMahon SB, Lewin G, Bloom SR (1991) The consequences of longterm topical capsaicin application in the rat. Pain 44:301-310.

McNeill DL, Westlund KN, Coggeshall RE (1989) Peptide immunoreactivity of unmyelinated primary afferent axons in rat lumbar dorsal roots. J Histochem Cytochem 37:1047-1052.

Mersky H, ed (1986) Classification of chronic pain: description of chronic pain syndromes and definition of pain terms. Pain [Suppl] 3: S1.

Olgart L, Gazelius B, Brodin E, Nilsson G (1977) Release of substance P-like immunoreactivity from dental pulp. Acta Physiol Scand 101: 510-512.

Owens CM (1991) Plastic changes in the responses of primate spinothalamic neurons, pp 86-89. PhD thesis, University of Texas Medical Branch.

Palmer E, Monaghan DT, Cotman CW (1989) Glutamate receptors and phosphoinositide metabolism: stimulation via quisqualate receptors is inhibited by $N$-methyl-D-aspartate receptor activation. Mol Brain Res 4:161-165.

Porszasz J, Jancso N (1959) Studies on the action potentials of sensory nerves in animals desensitized with capsaicin. Acta Physiol Acad Sci Hung 16:299-306.

Randic M, Hecimovic H, Ryu PD (1990) Substance P modulates glutamate-induced currents in acutely isolated rat dorsal horn neurones. Neurosci Lett 117:74-80.

Russell LC, Burchiel KJ (1984) Neurophysiological effects of capsaicin. Brain Res Rev 8:165-176.

Salt TE, Hill RG (1983) Pharmacological differentiation between responses of rat medullary dorsal horn neurons to noxious mechanical and noxious thermal cutaneous stimuli. Brain Res 263:167-171.

Schaible H-G, Schmidt RF, Willis WD (1987) Enhancement of the responses of ascending tract cells in the cat spinal cord by acute inflammation of the knee joint. Exp Brain Res 66:489-499.

Schaible H-G, Jarrott B, Hope PJ, Duggan AW (1990) Release of immunoreactive substance $\mathrm{P}$ in the spinal cord during development of acute arthritis in the knee joint of the cat: a study with antibody microprobes. Brain Res 529:214-223.

Schneider SP, Perl ER (1985) Selective excitation of neurons in the mammalian spinal dorsal horn by aspartate and glutamate in vitro: correlation with location and excitatory input. Brain Res 360:339343.

Schouenbory J, Dickenson A (1988) Long-lasting neuronal activity in rat dorsal horn evoked by impulses in cutaneous fibres during noxious mechanical stimulation. Brain Res 439:56-63.

Simone DA, Ngeow JYF, Putterman GJ, LaMotte RH (1987) Hyperalgesia to heat after intradermal injection of capsaicin. Brain Res 418:201-203.

Simone DA, Baumann TK, Collins JG, LaMotte RH (1989) Sensi- tization of cat dorsal horn neurons to innocuous mechanical stimulation after intradermal injection of capsaicin. Brain Res 486:185189.

Simone DA, Sorkin LS, Oh U, Chung JM, Owens C, LaMotte RH, Willis WD (1991) Neurogenic hyperalgesia: central neural correlates in responses of spinothalamic tract neurons. J Neurophysiol 66:228246.

Theriault E, Otsuka M, Jessell T (1979) Capsaicin evoked release of substance $P$ from primary sensory neurons. Brain Res 170:209-213.

Vlachova V, Vyklichy L, Vyklicky L Jr, Vyskocil F (1987) The action of excitatory amino acids on chick spinal cord neurones in culture. J Physiol (Lond) 386:425-438.

Watkins JC, Evans RH (1981) Excitatory amino acid transmitters. Annu Rev Pharmacol Toxicol 21:165-204.

Westlund KN, McNeill DL, Patterson JT, Coggeshall RE (1989) Aspartate immunoreactive axons in normal rat $\mathrm{L} 4$ dorsal roots. Brain Res 489:347-351.

Westlund KN, Carlton SM, Zhang D, Willis WD (1990a) Direct glutamergic innervation of primate spinothalamic tract neurons. Soc Neurosci Abstr 16:704.

Westlund KN, McNeill DL, Coggeshall RE (1990b) Glutamate immunoreactivity in rat dorsal root axons. Neurosci Lett 96:13-17.

Wiesenfeld-Hallin Z, Hokfelt T, Lundberg JM, Forssman WG, Reinecke M, Tchopp FA, Fischer JA (1989) Immunoreactive calcitonin generelated peptide and substance $P$ coexist in sensory neurons to the spinal cord and interact in spinal behavioral responses of the rat. Neurosci Lett 52:199-204.

Wilcox GL (1991) Excitatory neurotransmitters and pain. In: Proceedings of the VIth world congress on pain (Bond MR, Charlton JE, Woolf CJ, eds), pp 97-117. Amsterdam: Elsevier.

Willcockson WS, Chung JM, Hori Y, Lee KH, Willis WD (1984a) Effects of iontophoretically released amino acids and amines on primate spinothalamic tract cells. J Neurosci 4:732-740.

Willcockson WS, Chung JM, Hori Y, Lee KH, Willis WD (1984b) Effect of iontophoretically released peptides on primate spinothalamic tract cells. J Neurosci 4:741-750.

Willis WD, Dougherty PM (1991) Potentiation of responses of monkey spinothalamic (STT) cells to excitatory amino acids accompanies the development of capsaicin-induced hyperalgesia. Soc Neurosci Abstr 17:1372.

Woolf CJ (1983) Evidence for a central component of post-injury pain hypersensitivity. Nature 306:686-688.

Woolf CJ, Thompson SWN (1991) The induction and maintenance of central sensitization is dependent on $N$-methyl-D-aspartic acid receptor activation; implications for the treatment of post-injury pain hypersensitivity states. Pain 44:293-299.

Zhang D-Z, Owens C, Willis WD (1991) Two forms of inhibition of spinothalamic tract neurons produced by stimulation of the periaqueductal gray and the cerebral cortex. J Neurophysiol 65:1567-1579. 